\title{
Experimental and Performance Assessment of Indonesian Biomass-Fired Based Stove with Internal Air Box using Coconut Shell
}

\author{
J.P. Simanjuntak ${ }^{1}$, E. Daryanto ${ }^{2}$, B.H. Tambunan ${ }^{3}$, Lisyanto $^{4}$, Robert Silaban ${ }^{3}$, Aditya \\ Putranto ${ }^{5}$ \\ \{djanterps@gmail.com\}
}

\begin{abstract}
Mechanical Engineering Department, Universitas Negeri Medan, Medan 20221, North Sumatera, Indonesia $^{1,2,4,5}$, School of Chemistry and Chemical Engineering, Queen's University Belfast United Kingdom ${ }^{3}$
\end{abstract}

\begin{abstract}
This paper presents an integrated performance evaluation of in-lab manufacturing own designed prototype biomass fired-stove used coconut shell as feedstock. Two different stoves in terms of air required for combustion supply mode;(1) external air box (EAB), (2) internal air box (IAB) mode were tested and assessed with respect to the following performance indicator such as water time to boil, specific fuel consumption, and thermal efficiency. The stoves tested were the forced draft modified rocket-stove types with a battery mini fan-assisted to induce draft to force the controlled air for combustion requirement into the stoves. Flame temperature wasrecorded and displayed using K-type thermocouple and thermometer indicator respectively. Specific fuel consumption (SFC), thermal power (Pth) and the thermal efficiency ( $\square$ th) were calculated using the water boiling test (WBT 4.2.3) version protocol. Results showed that the internal air box (IAB) mode has higher thermal efficiency (38\%), specific fuel consumption $(2.5 \mathrm{~kg} / \mathrm{h})$, and flame temperature $(5000 \mathrm{C})$ than external air box $(\mathrm{EAB})$ mode. However, the thermal output of the $\mathrm{EAB}(2.3 \mathrm{~kW})$ was reached higher compare to IAB mode. The findings were used to improve the current biomass fired-stoves further that usually used for heating and cooking applications in rural communities.
\end{abstract}

Keywords: Biomass, Stove, Combustion

\section{Introduction}

Currently around $35 \%$ of the world's population uses biomass as a source of energy for heating needs. This happens because there are still many remote areas that have not been reached by the electricity, fuel oil and also gas. Besides, the price of gasoline and gas also continue to increase making people's purchasing power becomes reduced and prefer to use alternative fuel especially biomass.

This amount will increase again by the year 2030 where almost half of the human population will use biomass as energy source (Priddle, 2002), and each family will need 2 tons of timber per year for cooking and heating purposes (Cookstoves, 2011). This will have an impact on the magnitude of the need for biomass-based fuels, especially solid wood fuels that can easily be obtained primarily by exploiting forests. 
Biomass is usually burned directly to get heat energy, but this will greatly affect the human environment for a long time. Carbon dioxide $(\mathrm{CO} 2)$ released into the atmosphere and can disrupt the human respiratory system. Sometimes carbon monoxide $(\mathrm{CO})$ is also formed by an imperfect combustion process and one of the most radical types of air pollutants that can lead to death in large numbers (Bertrand et al, 2017).

Until now, biomass combustion technology using stove continues to grow. The combustion zone was designed, modified and tested to obtain the expected performance at least closer to the performance of the stove using LPG or kerosene as fuel. However, since the combustion reaction is usually not stoichiometric, where excess air is supplied to the stove will produce a high temperature (950-1000) 0C in combustion zones. High temperatures will trig the reaction of the formation of nitrogen oxide (NO) pollutants, where nitrogen in the air reacts with oxygen to form carbon monoxide $(\mathrm{CO})$. Besides causing pollution, fine particles, unburned carbon will also formed and released into free air with combustion gases.

Not only in the use of primary/fossil fuel sources, the use of energy sources from biomass also causes negative impacts on the environment (global impact warming), especially air pollution around the indoor air pollution that can cause respiratory infections. Not only in the country, abroad also experience the same problem that residents who use biomass fuel experience problems in breathing.

Direct combustion generates emissions gases and also smoke that is bad for the environment. Until now the atmospheric temperature has increased and sometimes the weather is very bad. Some references say that the impact of burning of primary fuel and also biomass is closely related to world climate change. Another problem arising from the use of biomass as a fuel directly by combustion is to produce unburned carbon particles. In industrial areas we often see and feel the unhealthy air condition and even often seen a real black cloud is a fine particle of fuel combustion. In such a large number that such circumstances will disturb the view, especially on air traffic, this will be very bad.

This study focused on evaluating the performance of two different biomass stove using coconut shell as feedstock. Specific objectiveis to obtain the type of air requirement distribution in the stove. Expected from this study that a prototype of biomass stove based the best air distribution is accieved. This prototype will also be used as a medium of learning in energy conversion courses related to heat energy, especially fuelcombustion technic.

\subsection{Biomass as Energy Alternative for the Future}

Biomass has been a source of energy alternative since the first in the development of human civilization in this world. In the early 1960s for example, the Indonesian government has begun to realize and glance at biomass as an alternative energy source. Besides being an environmentally friendly and renewable energy source, production is also abundant considering Indonesia is an agrarian country with significant biomass production. Based on the data from the Ministry of Energy and Mineral Resources that the energy source of biomass equivalent to $50,000 \mathrm{MW}$ is slightly below the energy source of water (hydropower). This indicates that biomass is very potential in contributing to energy needs in Indonesia as well as reducing dependence on primary energy sources. In the national energy plan, by 2025 the government targets $15 \%$ of the energy comes from renewable energy and that's $5 \%$ of it is contributed by biomass (Indonesia, 2004). 
Biomass energy studies have also been conducted by several researchers in Indonesia.By increasing biomass quality has a great contribution to its burning rate. This have been proven experimentallythatin combustion of biomass of cocoa pod husk (CPH) after doing carbonization treatment hassignificant increase in the burning rate(Syamsiro et al, 2012).

An Efforts to increase the value of product gas (syngas) heating value has also been conductedby improving the ability of the reactor. A new method of gasification has sucsessfully developed and implemented experimentallyto increae heating value of product gas. The value of syngas from sawdust biomass can reach almost $7 \mathrm{MJ} / \mathrm{m} 3$ when be processed in a concentric cylindrical fluidized bed with internally particle circulation mode (Simanjuntak \& Zainal, 2015).

Numerous effort were undertaken to improve performance of a new developed reactor. Modelling and experimentalvalidation are usually used to study the reactor characteristics. Particle hydrodynamic in the concentric cilynders with internally circulation for biomass gasification can be observed using modelling. It has been found that by increasing the particle circulation in the concentric two compartement cylindersreactor followed by increasing particle flow rate(Simanjuntak et al, 2018b). Since the particles acts as a heat transfer medium in gasification process, the energy for the process is always available. This finding support the result found that heating value of syngasincrease with the particle circulation rate(Simanjuntak \& Zainal, 2015).

Interms of biomass utiliation in Indonesia, a great literature study on the possibility of biomass utilization to fuel internal combustion engine has been conducted. It was concluded that with the calorific value of the gas product from the biomass of about $3 \mathrm{MJ} / \mathrm{m} 3$ it can be used to drive spark ignition combustion engines to replace of petroleum (Simanjuntak et al, 2018a).

\subsection{Biomass-Fired Stove Performance and Development Study}

It has been long time ago that to get energy from biomass is conducted through direct combustion. The biomass is collected, dried and burned as necessary. The stove used is very simple, i.e three fireproof objects or (three stones)which arranged with a pot holder where the object will be heated(Grimsby et al., 2016. At that time the efficient way of burning biomass is not known and the combustion process is also very simple. The combustion process is done in an open environment by utilizing the surrounding air as oxidizer. This makes the combustion process unfavorable and result very much pollutant and fine particles that are very bad for health. The process of burning using stoves began in the 1980s, but the problem of stove ability is not important. Until the 1990's studied of improving stove materials / materials ranging from clay and sand, the shape is modified fitted to a chimney to overcome the problem of pollution. But on the matter of age (life time), this stove cannot last long. In improving furnace capability, knowledge of heat transfer also began to be considered until in early 2000's a strong, heat-resistant furnace material began to be taken into account. Some researchers tried to make some effort of improvements and modifications to the stove, including construction, materials, and operation parameters includee air supply and distribution in the combustion zone of the stove. Especially in the method of combustion, researchers continue to attempt to combustion process to near complete combustion. The perfect combustion process generates maximum heat and reduces emissions.

Some researchers tried to make an effort to improve and modify the stoves including geometry, materials, operating parameters including air supply into the stove.Biomass types and characterstics has a significant impact on the heating value. An effort has been done to 
evaluate the combustion of biomass in a furnace and focuses on testing of certain types of biomass as fuel. Three stoves were tested and evaluated with 3 forced-draft kilns and two types of biomass to determine furnace efficiency(Raman et al, 2013).Furthermore, biomass energy can be converted into another useful type. Electrical can be obtained from biomass stove. A study of 5 small-scale stoves to generate electrical energy using thermoelectric generators (TEGs) has been conducted. However, eeach type of biomass used also has a different impact on the environment(O'Shaughnessy et al, 2015). Similiar findings, a study of 5 types of biomass in terms of emissions generated during the combustion process has also performed. It was found that the biomass type greatly affects the emissions and the resulting fine particles(Vicente et al, 2015).

Another parameter that important to know during biomass combustin,numerous types of stoves also need to investigate. A group researches studied several types of stoves and itsoperating temperatures in terms of producing fine particles. They concluded that different stove designs would produce different fine particles also. They also undertook parameter studies of biomass stoves to determine parameters that were the main focus in the design and operation of a biomass furnace(L'Orange et al, 2012).

The biomass cal also formed to another form ficically. The briquettes blended with rice husk were also used as feedstock in biomass stove. A succesful research obtained $6 \mathrm{~kW}$ of electrical energy from the stove (Ahiduzzaman \& Islam, 2013).Another group laboratory also investigated the efficiency of a biomass fired stove with palm shell as solid fuel. They managed to get stove efficiency up to $66.63 \%$ based on modified stove geometry and operating parameters(Febriansyah et al, 2014).

Environ quality is also has to be considered due to the effect of using solid fuels as heatgenerating energy. Fine particles of combustion that fly into free air are very harmful to human respiration. Studies on biomass burning furnaces are also widely practiced considering they are very practical for generating heat energy. (Semmens et al, 2015). The most contributed to environment damage are the gas product that saccrivice to asmosphere. By using briquette as solid fuel, it was found that $\mathrm{CO}$, NOx and $\mathrm{SO} 2$ were the most widely generated pollutant components(Roy et al., 2013.

According to these researches findings, it can be summarised that one of important aspect on improving the fired-stove performance is to acchive complete combustion process. In order to attain complete combustion, the good air combustion requirement distribution is needed. A number of researcher studied and focused on air combustion requirement, but the information on the effect of internal air box (IAB) utilization on the stove performance is not available. The IAB mode is an attractive and promissing stove geometry to attain good mixing between air and flameable gas during combustion process. Thus, the objective of this study is to find out the impact of IAB application on the stove performance. An improved biomass fired stove, an external air box (EAB) mode was also tested to compare the results found from the IAB fired stove examination.

\subsection{Stove Design and Construction}

Forced draft stoves type with internal air distributor used in this study were designed. The stoves are made and modified from the used can of aluminium material, easy to obtain that usually as household waste. Both stoves working principle are force draft type based where a controlled air for combustion needed is supplied by a mini battery fan. 

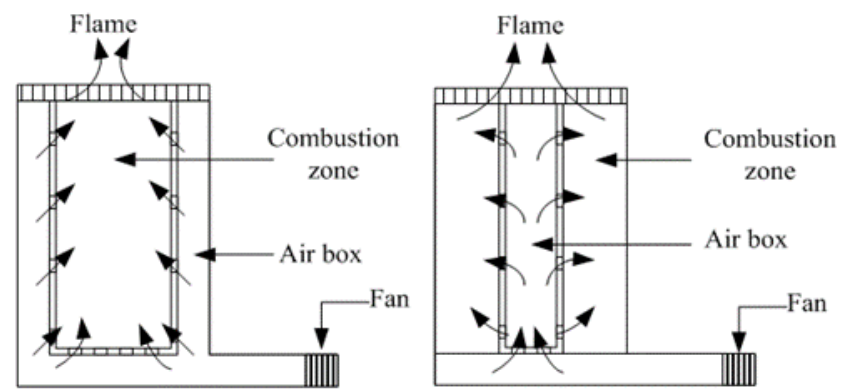

Figure 1: Stove schematic diagram with air distribution mode: (a) External air box (EAB) mode, (b) Internal air box (IAB) mode

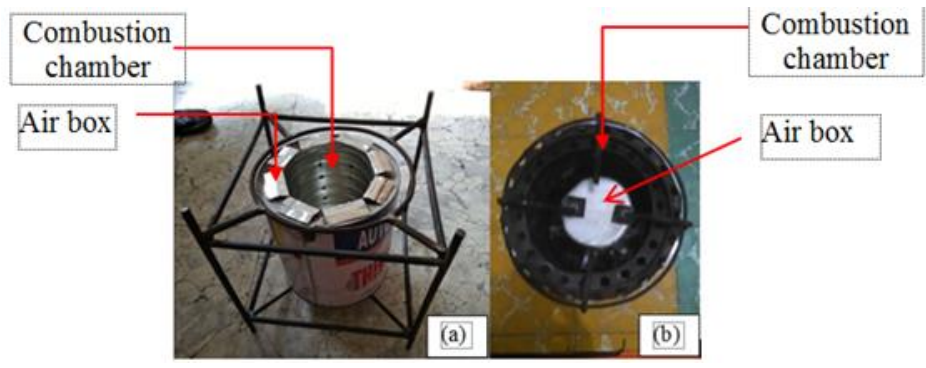

Figure 2: The stoves prototype: (a) External air box, (b). Internal air box

The stoves configuration can be seen inError! Reference source not found..An important key factorof high thermal output of biomass combustion is air fuel ratio aspect. A good combustion must required enough oxygen. However, without good air distribution in the combustion zone, the combustion does not reach a complete level. Thus in this stove operation, maintaining and controlling a fixed ratio betweenthe amounts of biomass and the air supplied into the stove is neede to meet the stoichiometric reaction during process. From layout of stove with internal plennum (Error! Reference source not found.b), a uniform mix between feedstock and air possible occured due to its posisition in the centre of the stove.

A number of holes with $8 \mathrm{~mm}$ in diameter drilled on the air-box wall were placed to ensure the air distribution. The air directly supplied in to the hot zone in the stove. The inernal air box is the most promissing of fan-operated stoves to carry out a complete combustion process. This type of stove also potential to reduce emission besides of improving in combustion and also the heat transfer to the cooking vessel. However in this work that the potential harmfull emission as a combustion product is not discussed.

\section{Materials And Method}

\subsection{Stove Design Construction and Material}

The stoves prototype designed in this work as shown in Figure 2. Clearly, the difference between the stove; external air box mode and the internal air box mode can be figured out easily. In Fig. 2(a) the air holes are placed on the wall of the cylinder of EAB mode, while Fig 2 (b) shown the opposit, where the air holes are placed on the wall of inner airbox of IAB. 
The coconut shell was selected as feedstock in this study. This material is most widely used for cooking purposes as described previously. This biomass consists of $54.52 \%$ carbon, the rest is ash or other chemical substances(Raman et al, 2013). Coconut shell is very easy to obtain because there are many home industries that use coconut shell as raw material. The bakery industry for xample also uses alot of coconut baking material and produces coconut shell as the rest of the processed. Usually, the coonut shell is found fisically as shown in Figure 3.

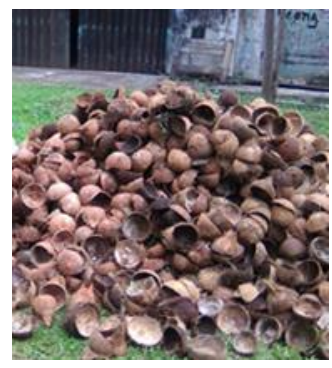

Figure 3. Coconut shell raw material

\subsection{Experimental Procedures, Instrument and Measurement}

In initiating the operation of a stove, start-up heating becomes very important. In this study, preheating or initial ignition was carried out using charcoal that usually available in the household store. About $25 \mathrm{~g}$ of charcoal was used to light the fire using matches. The charcoal was considered well-lit when it's colour was fisually observed fully red. Afterwards, $250 \mathrm{~g}$ of coconut shell with approximately $5 \mathrm{~cm} \times 5 \mathrm{~cm}$ in sizes are fed into the stove precisely above the grate along with 1 litre of water in the closed pan located on the grid at the top of the stove.The time required for initial ignition should be as short as possible until the stovegenerated flame. Three experiments were conducted witch both stoves once the stove was ready to test. After the fire arises from the stove, the experimental process begins, the fan air supply was turned on and the air flow was measured using anemometer.

The flame temperatures during the test-run were measured using a K-type thermocouple, viewed and recorded using a digital temperature indicator.Mass balance is used to measure the mass of biomass, ash and water while the time is measured using stop watch of smart phone. In order to accieve maximum thermal energy from biomass, the operating parameters used must accordance with the theory. Air-fuel ratio should be appropriate for stoichiometric combustion. A complete combustion does not produce oxygen in the combustion product. The main product of combustion are $\mathrm{CO}_{2}$ and $\mathrm{H}_{2} \mathrm{O}$ of stoichiometric combustion.

To evaluate the performance of the designed fired-stove, the modified water boiling test (WBT 4.2.3)version was performed due to the lack of the instrument in the laboratory. The results were carefully consulted to the standar protocol WBT under numerous work. WBT protocol has been widely used to assess improved stove. This method has been used to evaluate the performance of solid fuel burning furnaces (Chen et al, 2016; Grimsby et al, 2016). 


\section{Results And Discussions}

Understanding the operation of both stovestested has been achievedthrough the visualobservations of the flames colour and temperature profiles during running-test. The stoves flames observed during experiment can be seen as shown in Figure 4. Clearly, the difference between the stove with external air box and the internal air box in terms of flames can be observed. The flame temperature of the stove-fired based is in the range of 400-500 0C where the water completely boiledaverage in 3 minutes and it is possible going to increase further due to potensial burning of the rest solid fuel in the stove. It was observed that the flame temperature from the IAB's stove is higher than the EAB's one. The higher the flame temperature indicated higher thermal power output of the stove. High temperature increased heat transfer rate to the water pot, thus making the fired stoves work at higher efficiency than the traditional stoves. It was also observed that both of the stoves have difference in colour. This type of colour indicated low heat level with the temperature below 1000 0C.

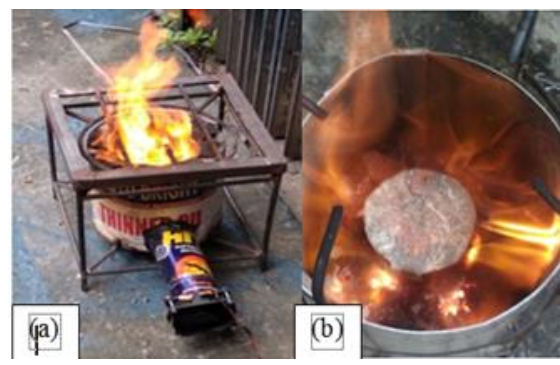

Figure 4: The stove flames photoghrapic in operation: (a) EAB stove's, (b) IAB stove's

Temperature profile of both stoves during process can be seen onFigure 5 . It was observed that the temperature of the IAB stove was higher than the EAB stove. This is because that the air/oxygen for combustion requirement distributed uniformly caused better mixing between combustible gas and oxygen leads to an increased in the combustion. This results in accordancewith results work by(Wibawa, 2017). In principle, combustion process initiated primary by pyrolysis and gasification process, where combustible gases emitted difuse and mix with the surrounding air. With sufficient air/oxygen, the gases will combust further in the same zone produced high temperature flue gas and leaving the stove. 


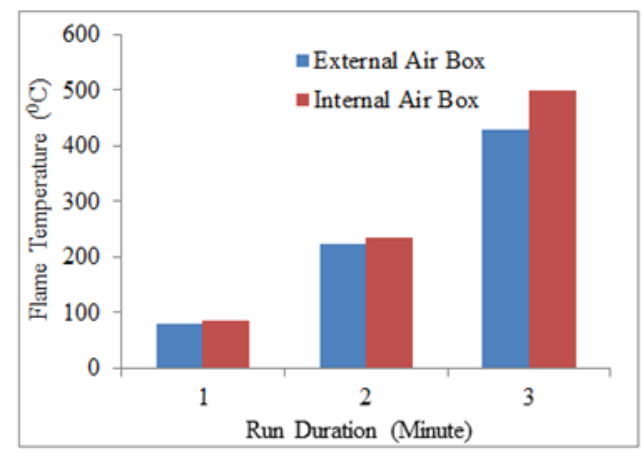

Figure 5: Flame temperature profile of stoves

In this study, performance of the stoves was evaluated by using the water boiling test (WBT) since this method perform well under some of difference in biomass and stove geometry. The performsnce parameters obtained from WBT were thermal efficiency, specific fuel consumption and also the thermal output of the stove. This protocol was also used by a number of researcher to evaluate their biomass fired stove (L'Orange et al, 2012; Raman et al, 2013). The findings in this work were alot of similar with another results founded by researches. Figure 6 shows the performance parameters obtained in this work. Thermal efficiency of the stove using coconut shell is found tobe similar with another researcher (Raman et al, 2013). While the specific fuel consumption and the thermal output power are quite comparable with previous researcher.

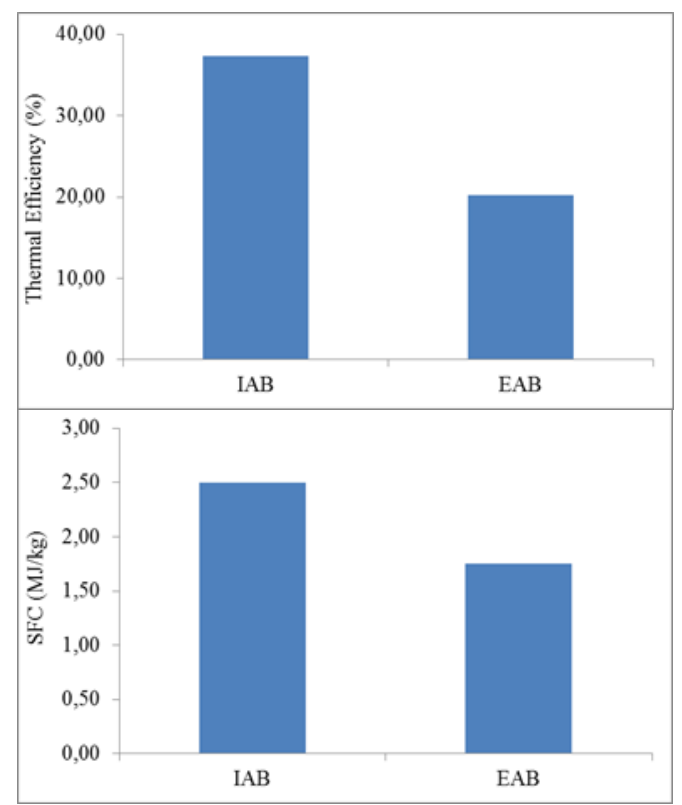




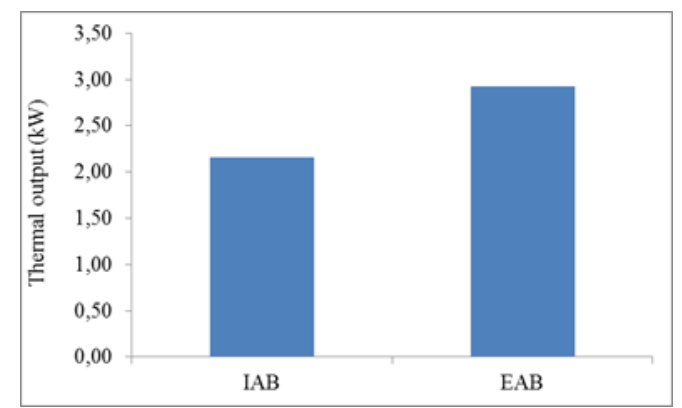

Figure 4: The stoves performance parameter

\section{Conclusion}

A new way onperformance improvement of biomass fired stove based in terms of air requirement supply for combustion was developed and tested. It was found that there was significant effect of the air distribution mode in the combustion zones on stove performances. Good mixing of gas product and oxygen contributed to the best performance of the stove in terms of flame temperture. In this study, it was found that the temperature of the flame strongly affected by the air distribution mode. Using internal air box mode (IAB) highly possible to distributeuniformly air required for combustion reached entire the combustion zone. Thus the performance of the biomass fired stove could be improved.

\section{Acknowledgments}

The authors would like to acknowledge Universitas Negeri Medan for financial support through DIPA, Number 000574/UN33/KU/2018, Marc 22, 2018. The authors was highly acknowledge supports from mechanical engineering workshop membetcengineering faculty, Universitas Negeri Medan and also all the student for their participation in this project.

\section{References}

[1] Somov, A.: Wildfire safety with wireless sensor networks. EAI Endorsed Transactions on Ambient Systems. pp. 1-11 (2011)

[2] Motaz, A.: Start programming using Object Pascal. Vol. 2, pp. 10-11. Legally Free Computer Books, US (2013)

[1] Ahiduzzaman, M. \& Islam, A. S.: Development of biomass stove for heating up die barrel of rice husk briquette machine. Procedia Engineering. pp. 777-781 (2013)

[2] Bertrand, A., Stefenelli, G., Bruns, E. A., Pieber, S. M., Temime-Roussel, B., Slowik, J. G., Prévôt, A. S. H., Wortham, H., El Haddad, I. \& Marchand, N.: Primary emissions and secondary aerosol production potential from woodstoves for residential heating: Influence of the stove technology and combustion efficiency. Atmospheric Environment. pp. 65-79 (2017)

[3] Chen, Y., Shen, G., Su, S., Du, W., Huangfu, Y., Liu, G., Wang, X., Xing, B., Smith, K. R. \& Tao, S.: Efficiencies and pollutant emissions from forced-draft biomass-pellet semi- 
gasifier stoves: Comparison of International and Chinese water boiling test protocols. Energy for Sustainable Development. pp. 22-30 (2016)

[4] Cookstoves, H.: Environment, Health, and Climate Change: A New Look at an Old Problem. The World Bank, Washington (2011)

[5] Febriansyah, H., Setiawan, A. A., Suryopratomo, K. \& Setiawan, A.: Gama stove: biomass stove for palm kernel shells in Indonesia. Energy Procedia, pp. 123-132. (2014)

[6] Grimsby, L. K., Rajabu, H. M. \& Treiber, M. U. Multiple biomass fuels and improved cook stoves from Tanzania assessed with the Water Boiling Test. Sustainable Energy Technologies and Assessments, pp. 63-73. (2016)

[7] Indonesia, S. E. E.: Pusat Informasi Energi dan Sumber Daya Mineral, Jakarta (2004)

[8] L'Orange, C., DeFoort, M. \& Willson, B.: Influence of testing parameters on biomass stove performance and development of an improved testing protocol. Energy for Sustainable Development. pp. 3-12 (2012)

[9] O’Shaughnessy, S. M., Deasy, M. J., Doyle, J. V. \& Robinson, A. J.: Performance analysis of a prototype small scale electricity-producing biomass cooking stove. Applied Energy. pp. 566-576 (2015)

[10] Priddle, R.: World energy outlook 2002. International Energy Agency, IEA/OECD, Paris (2002)

[11] Raman, P., Murali, J., Sakthivadivel, D. \& Vigneswaran, V.: Performance evaluation of three types of forced draft cook stoves using fuel wood and coconut shell. biomass and bioenergy. pp. 333340 (2013)

[12] Semmens, E. O., Noonan, C. W., Allen, R. W., Weiler, E. C. \& Ward, T. J.: Indoor particulate matter in rural, wood stove heated homes. Environmental research. pp. 93-100. (2015)

[13] Simanjuntak, J., Daryanto, E., Tambunan, B. \& Lisyanto: Producer gas production of Indonesian biomass in fixed-bed downdraft gasifier as an alternative fuels for internal combustion engines, Journal of Physics: Conference Series. IOP Publishing (2018a)

[14] Simanjuntak, J. P., Alattab, K. \& Zainal Alauddin, Z. A.: Hydrodynamic flow characteristics in an internally circulating bubbling fluidized bed gasifier. Journal of Energy Resources Technology (2018b)

[15] Simanjuntak, J. P. \& Zainal, Z. A.: Experimental study and characterization of a twocompartment cylindrical internally circulating fluidized bed gasifier. Biomass and Bioenergy. pp. 147-154 (2015)

[16] Syamsiro, M., Saptoadi, H., Tambunan, B. H. \& Pambudi, N. A.: A preliminary study on use of cocoa pod husk as a renewable source of energy in Indonesia. Energy for Sustainable Development. pp. 74-77. (2012)

[17] Vicente, E. D., Duarte, M. A., Tarelho, L. A. C., Nunes, T. F., Amato, F., Querol, X., Colombi, C., Gianelle, V. \& Alves, C. A.: Particulate and gaseous emissions from the combustion of different biofuels in a pellet stove. Atmospheric Environment. pp. 15-27. (2015)

[18] Wibawa, U. Pendekatan Praktis Pembangkit Energi Baru \& Terbarukan Universitas Brawijaya Press, Malang (2017) 